\title{
PARTIAL REPLACEMENT OF COARSE AGGREGATES BY EXPANDED POLYSTYRENE BEADS IN CONCRETE
}

\author{
Thomas Tamut $^{1}$, Rajendra Prabhu ${ }^{2}$, Katta Venkataramana ${ }^{3}$, Subhash C Yaragal $^{4}$ \\ 1 PG Student, Dept. of Civil Engineering, National Institute of Technology, Karnataka, India \\ 2 Research Scholar, Dept. of Civil Engineering, National Institute of Technology, Karnataka, India \\ $3 \& 4$ Professors, Dept. of Civil Engineering, NITK, India
}

\begin{abstract}
With the increase in demand for construction materials, there is a strong need to utilize alternative materials for sustainable development. The main objective of this investigation is to study the properties, such as compressive strength and tensile strengths of lightweight concrete containing Expanded Polystyrene (EPS) beads. Its properties are compared with those of the normal concrete i.e., without EPS beads. EPS beads are used as partial replacement to coarse aggregates. The results showed that the amount of polystyrene beads incorporated in concrete influences the properties of hardened concrete. At 28 days, it was found that compressive strength of 5\%, 10\%, 15\%, 20\%, 25\% and 30\% EPS incorporated concrete strengths were 91\%, 77\%, 71\%, 63\%, 57\%, and 45\%, respectively when compared to concrete with no EPS case.
\end{abstract}

Key Words: Expanded polystyrene beads (EPS); Workability; Compressive strength; Splitting tensile strength; - ***.

\section{INTRODUCTION}

Increase in the developmental activities world over, the demand for construction materials is increasing exponentially. This trend will have certainly greater impact on the economic system of any country. India also is aiming at a high developmental rate compared to other nations in Asia. There is heavy demand for the building materials in the domestic market, which is becoming scarce day by day. At this point researchers and engineers who have the foresight to keep the developmental activities abreast and curtail the cost factor should look out for other alternative building materials.

In this work, an attempt is made to address the possibility of utilizing Expanded Polystyrene (EPS), a packing material in the form of beads in concrete, which otherwise is posing a threat to waste disposal as well as for waste management. This material is a cause of concern to environmentalists. In this study, it is attempted to partially replace coarse aggregates by means of EPS beads. A general discussion on EPS, its production and its application along with environmental concerns are being discussed.

Expanded polystyrene (EPS) is a lightweight cellular plastics material consisting of fine spherical shaped particles which are comprised of about $98 \%$ air and $2 \%$ polystyrene. It has a closed cell structure and cannot absorb water. It has a good sound and thermal insulation characteristics as well as impact resistance. Polystyrene foam is a non-biodegradable material.
It is a waste material from packaging industry. It creates disposal problem. Utilizing crushed polystyrene granules in concrete is a valuable waste disposal method.

There are many advantages to be gained from the use of lightweight concrete. These include lighter loads during construction, reduced self-weight in structures, and increased thermal resistance. Lightweight concrete is generally accepted as concrete having a density of about $1800 \mathrm{~kg} / \mathrm{m}^{3}$ or less. The present investigation was taken up, keeping two targets in view, disposal of the polystyrene waste from the point of view of environment and for the replacement of aggregate from the point of view of construction industry. The present study aims at utilization and the suitability of polystyrene beads as coarse aggregate. A comparative study on strength parameters is also done against conventional concrete to study the behavior of the polystyrene aggregate. For this $5 \%, 10 \%, 15 \%, 20 \%, 25 \%$ and $30 \%$ replacement of coarse aggregate by expanded polystyrene beads is attempted in this work.

\subsection{MATERIALS AND METHODS}

The test procedures for assessing the quality of various materials that are used for preparation of test concrete are detailed. The types of tests on fresh and hardened concrete are also described in detail. Expanded polystyrene (EPS) is a lightweight cellular plastics material consisting of fine spherical shaped particles which are comprised of about $98 \%$ air and $2 \%$ polystyrene. It has a 


\subsection{Materials}

The ingredients of concrete were Expanded Polystyrene beads in the form of spheres, (used for filling bean bags), River sand as fine aggregate, crushed granite stones as coarse aggregate, 43 grade Ordinary Portland Cement conforming to I.S: 8112 and water. The physical properties EPS beads related to the work are shown in Table1.

Table 1: Properties of expanded polystyrene beads

\begin{tabular}{|c|c|c|}
\hline Specific Gravity & Bulk density & Particle size \\
\hline 0.011 & $6.86 \mathrm{~kg} / \mathrm{m}^{3}$ & $\begin{array}{c}\text { Spherical } \\
(8-9 \mathrm{~mm} \text { dia })\end{array}$ \\
\hline
\end{tabular}

\subsection{Experimental program}

The physical properties of individual ingredients were determined. The mix proportions for M30 conventional concrete mix was arrived as per IS: 10262-2009.

Adopting w/c $=0.46$, the proportion of concrete mix is,

$\begin{array}{ccccccc}\mathrm{W} & : & \mathrm{C} & : & \mathrm{FA} & : & \mathrm{CA} \\ 200 & : & 434 & : & 660.67 & : & 999.5 \\ 0.461 & : & 1.000 & : & 1.522 & : & 2.303\end{array}$

This concrete mix proportion is taken as the reference or control mix in the present study. The mix proportion for EPS beads based concrete is obtained by partially replacing coarse aggregate with different dosages of polystyrene beads volumetrically. The quantities of materials for various mixes are obtained by partial replacement (by volume) of coarse aggregates by EPS beads.

Cubes of $150 \mathrm{~mm}$ size for compressive strength evaluation and cylinders of $150 \mathrm{~mm}$ diameter for split tensile tests were prepared. The specimens were cured in water for 28 days and then tested. For every mix, 6 cubes of $150 \mathrm{~mm}$ size (for compression tests: 3 numbers each for 7 days and 28 days), and 3 cylinders of $150 \mathrm{~mm}$ diameter and $300 \mathrm{~mm}$ height for split tensile test were cast. Six levels of replacement of aggregate were considered, i.e., 5, 10, 15, 20, 25 and 30\%.

\subsection{Tests on EPS based concretes}

\subsubsection{Workability}

The slump test is the most well-known and widely used test method to characterize the workability of fresh concrete.

\subsubsection{Compressive Strength}

Strength of concrete is the most important, although other characteristics may also be critical and cannot be neglected. Strength is an important indicator of quality because strength is directly related to the structure of hardened cement paste. Even though strength is not a direct measure of durability or dimensional stability, it has a strong relationship with the water to cement ratio of the concrete, which in turn influences durability, dimensional stability and other properties of concrete.

\subsubsection{Split Tensile Strength}

Tensile strength governs the cracking behavior and affects other properties such as stiffness, damping action, and durability of concrete. It is also important regarding the behavior of concrete under shear loads. Tensile strength is determined by either direct tensile tests or by indirect tensile tests such as flexural or split cylinder tests in accordance with national standards.

\subsection{RESULTS AND DISCUSSION}

\subsection{General}

In this section, results of the various tests conducted on both control and Polystyrene concrete mixes, both in their fresh and in hardened states are discussed. In fresh state, their workability, and in hardened state, their mechanical properties (compressive and split tension) at 7-days and 28-days of curing are discussed and are evaluated.

\subsection{Fresh concrete mixes}

In general, it was observed that workability of a concrete mix increased on addition of polystyrene. Workability of the mixes was observed to increase with increase in percentage replacement of coarse aggregate with polystyrene (as a partial replacement of aggregate) i.e., higher the polystyrene replacement, higher was the workability. Bleeding was observed with the increase in water/cement ratio. Compactions of the specimen were done with vibrating machine, high degree of vibration resulted in segregation of polystyrene beads from the rest and bleeding occurred. The slump values obtained are tabulated in Table 2.

Table 2: Variation in slump with EPS (\%)

\begin{tabular}{|c|c|c|}
\hline $\begin{array}{c}\text { Sl. } \\
\text { No. }\end{array}$ & $\begin{array}{c}\text { EPS } \\
\text { Replacement } \\
(\boldsymbol{\%})\end{array}$ & Slump (mm) \\
\hline 1 & 0 & 35 \\
\hline 2 & 5 & 35 \\
\hline 3 & 10 & 40 \\
\hline 4 & 15 & 42 \\
\hline 5 & 20 & 45 \\
\hline 6 & 25 & 55 \\
\hline 7 & 30 & 60 \\
\hline
\end{tabular}

\subsection{Tests on hardened concrete}

\subsubsection{Compression Tests}

Compression testing of the cube specimens was carried out in a Universal Testing Machine of capacity $2000 \mathrm{kN}$, as per IS: 516-1959. The load was applied without shock at a rate of $140 \mathrm{~kg} / \mathrm{sq} . \mathrm{cm} / \mathrm{min}$. A set of three cubes were tested for each of the mix for their compressive strengths at 7 and 28 days of 
curing. The ultimate load at which specimen failed was noted down for each specimen. Linear average was calculated over three specimens, provided the individual variation was not more than \pm 15 percent of the average. Specimens after testing were visually inspected for the rupture surface and polystyrene beads distribution. The results of compression test are shown in Figure 1.

It is seen that the compressive strength of all concrete mixes increased with the increase of age. It is observed that, the larger the amount of polystyrene beads in concrete, the lesser the compressive strength. As expected, the normal weight concrete has more compressive strength at all ages compared to lightweight concrete. At 28 days, it was found that compressive strength of $5 \%, 10 \%, 15 \%, 20 \%, 25 \%$ and $30 \%$ EPS based concretes compared to control concrete were $91 \%$, $77 \%, 71 \%, 63 \%, 56 \%$, and $45 \%$, respectively.

It can be observed that the compressive strengths of all the

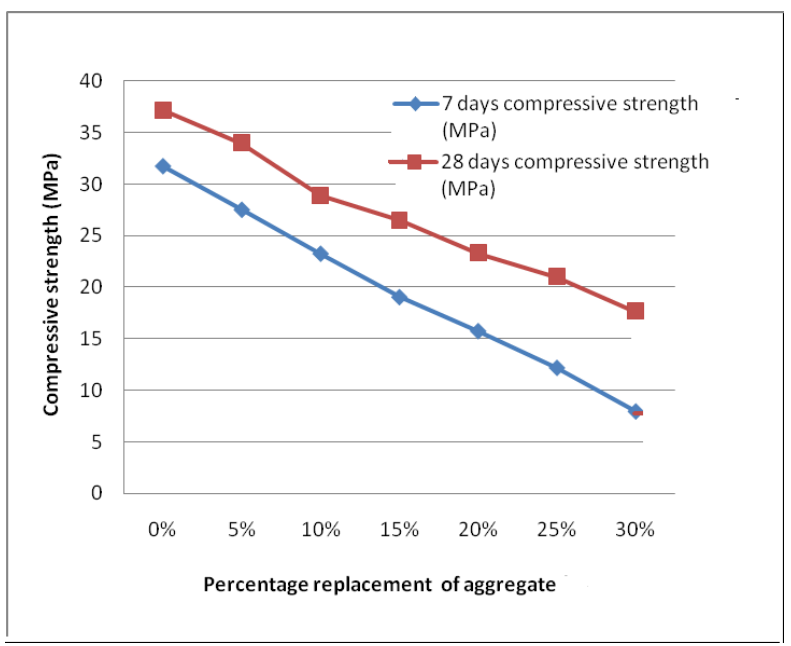

Fig. 1: Compressive strength variation percentage of EPS variation

EPS based concrete mixes, in general, decrease with an increase in polystyrene beads content. This can be attributed to,

a. Increase in polystyrene volume, increases the voids as compared to the control mix.

b. Smooth surface of the polystyrene; hence the polystyrene beads tend to bond loosely with the cement paste. It is seen that the polystyrene particles could be easily plucked and removed from the rupture surfaces of the cubes after compression tests. Due to this poor bond characteristic, failure takes place through the cement paste- polystyrene interface at much lower stress levels.

c. Low specific gravity of the polystyrene due to which there is a reduction in overall density of the concrete. Density affects the compressive strength i.e., an increase in the density of the mix will increase its compression strength.

In $0 \%$ EPS (control concrete), at 7 days the compressive strength was $31.77 \mathrm{MPa}$, and then at 28 days it increased considerably to $37.18 \mathrm{MPa}$. In 5\%, 10\%, 15\%, 20\%, 25\% and $30 \%$ EPS based concretes on the other hand, the compressive strength increased from 7 days to 28 days, the absolute difference was about 6 to $9 \mathrm{MPa}$.

\subsubsection{Split Tensile Tests}

Split tensile tests were carried out, on standard cylindrical specimens of all the EPS based concrete mixes, as per IS 5816: 1999. This is an indirect method of applying tension in the form of splitting. The test was performed on the cylinders of $150 \mathrm{~mm}$ diameter and $300 \mathrm{~mm}$ height, as per I.S. specifications. The specimen is placed with its axis horizontal between the platens of testing machine. Thin strips of $12 \mathrm{~mm}$ wide and $3 \mathrm{~mm}$ thick were inserted between the cylinder and the platens of testing machine. The load increment of 140 $\mathrm{kN} /$ minute was applied until the failure by splitting along the vertical diameter took place. The stone aggregates and EPS beads were uniformly distributed in the matrix as shown in the Fig. 2.

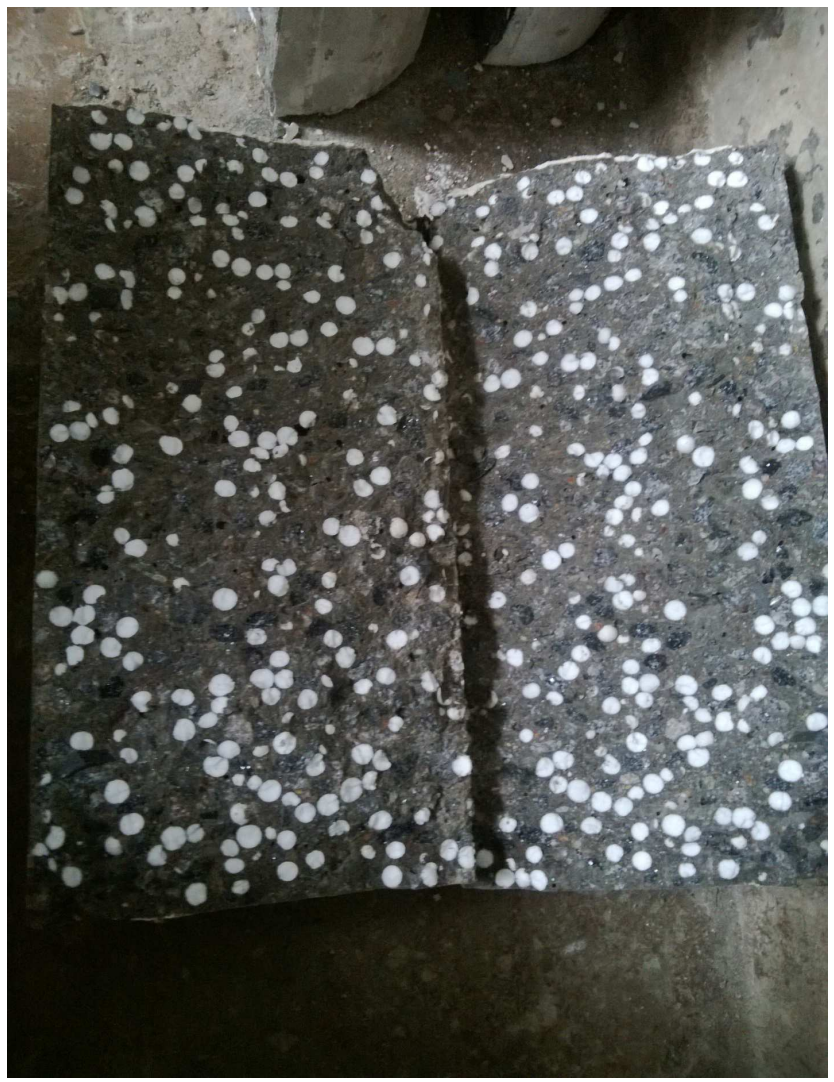

Fig. 2: Broken surfaces of failed cylinders 
The results of split tensile tests are presented in Fig.3. It is clear from the bar chart that, the higher the amount of polystyrene beads in concrete mixture, the lower the tensile strength. Mix with $15 \%$ EPS has a relative strength of $80 \%$ and that with $30 \%$ EPS has a relative strength of $70 \%$.

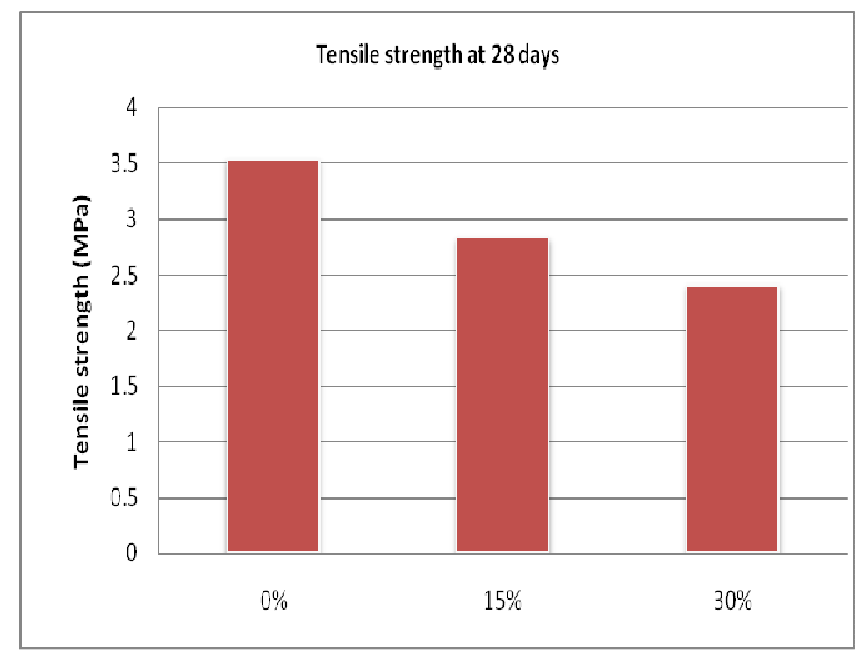

Fig. 3: Split Tensile strength at 28 days

\section{CONCLUSIONS}

The following conclusions were drawn from the study.

1. Increase in the EPS beads content in concrete mixes reduces the compressive and tensile strength of concrete.

2. All the EPS concrete without any special bonding agent show good workability and could easily be compacted and finished.

3. Workability increases with increase in EPS beads content.

4. The replacement by using EPS has shown a positive application as an alternate material in building nonstructural members, and it also serves as a solution for EPS disposal.

5.

Obtained results suggest that expanded polystyrene concrete has scope for nonstructural applications, like wall panels, partition walls, etc.

\section{REFERENCES}

[1] IS 383:1970 "Specifications for coarse and fine aggregates from natural sources for concrete", Bureau of Indian Standards, New Delhi.

[2] IS 456: 2000 - 'Code of practice for plain and reinforced concrete', Bureau of Indian Standards, New Delhi.
[3] IS 516: 1959 (Reaffirmed 1999) "Methods of Test for Strength of Concrete", Bureau of Indian Standards, New Delhi

[4] IS 2386:1963 "Methods of tests for aggregates for concrete", Bureau of Indian Standards, New Delhi

[5] IS: 8112:1989, "Specification for 43 grade ordinary Portland cement" Bureau of Indian Standards, New Delhi.

[6] IS: 10262: 1982, "Recommended guidelines for concrete mix design" Bureau of Indian Standards, New Delhi

\section{BIOGRAPHIES:}

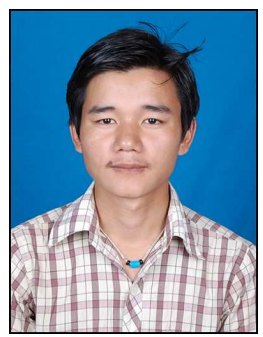

Thomas Tamut, P.G Student, graduated in Civil Engineering from Basaveshwar Engineering College, Bagalkot, Karnataka, in the year 2011.

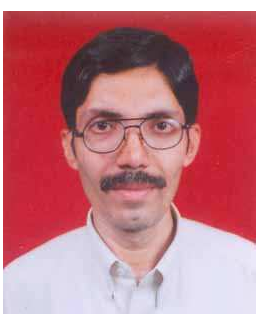

Mr. Rajendra Prabhu obtained his B.E (Civil) and M. Tech (Structural Engg.) from MIT, Manipal. He worked in the areas of consultancy, teaching and ready mix concrete industry. Currently he is pursuing his doctoral degree in the area of concrete technology in NITK, Surathkal.

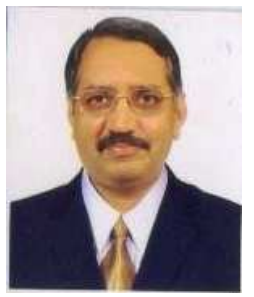

Prof. Katta Venkataramana graduated from NIE Mysore, did his Master's degree from Kagoshima University, Japan. He obtained his doctoral degree from University of Kyoto, Japan. He is serving as Professor in the department of Civil Engineering, NITK, Surathkal from 2002. Currently he is also discharging his duties as Head of the Department. His areas of research interests include Earthquake engineering and Earthquake resistant design, concrete technology, etc.

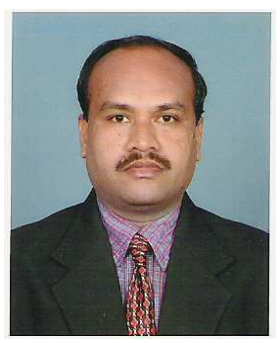

Dr. Subhash C Yaragal graduated from NITK Surathkal and obtained his post graduation and doctoral degrees from the Indian Institute of Science, Bangalore. Currently he is serving as Professor and Associate Dean (Academic). His areas of interest include concrete technology, concrete performance, pipeline engineering and building aerodynamics and wind tunnel testing. 